ournal of Health Services Research \&

\title{
Demand-side strategies to deal with moral hazard in public insurance for long-term care
}

(C) The Author(s) 2015

Reprints and permissions:

sagepub.co.uk/journalsPermissions.nav DOI: $10.1177 / 1355819615575080$ jhsrp.rsmjournals.com

(SAGE

\author{
Pieter Bakx', Dov Chernichovsky², Francesco Paolucci', \\ Erik Schokkaert ${ }^{4}$, Maria Trottmann ${ }^{5}$, Juergen Wasem ${ }^{6}$ \\ and Frederik Schut ${ }^{7}$
}

\begin{abstract}
Moral hazard in public insurance for long-term care may be counteracted by strategies influencing supply or demand. Demand-side strategies may target the patient or the insurer. Various demand-side strategies and how they are implemented in four European countries (Germany, Belgium, Switzerland and the Netherlands) are described, highlighting the pros and cons of each strategy. Patient-oriented strategies to counteract moral hazard are used in all four countries but their impact on efficiency is unclear and crucially depends on their design. Strategies targeted at insurers are much less popular: Belgium and Switzerland have introduced elements of managed competition for some types of long-term care, as has the Netherlands in 2015. As only some elements of managed competition have been introduced, it is unclear whether it improves efficiency. Its effect will depend on the feasibility of setting appropriate financial incentives for insurers using risk equalization and the willingness of governments to provide insurers with instruments to manage long-term care.
\end{abstract}

\section{Keywords}

long-term care, managed competition, public insurance, risk adjustment

\section{Introduction}

Affordable, universal, comprehensive insurance helps to ensure access to long-term care (LTC) for the elderly. But LTC insurance suffers from ex-post moral hazard because patients do not bear the full cost of the services that they use and because insurance gives their relatives an incentive to stop providing informal care. Moral hazard causes substitution of more expensive formal LTC both for informal care and for less expensive LTC and may increase the number of people who claim benefits. Thus, moral hazard leads to use beyond the point where the marginal benefits equal the marginal costs.

The negative consequences of moral hazard may be mitigated by strategies limiting the supply - targeting providers - or the demand for LTC - targeting patients or insurers. This article is about the latter, which may consist either of cost sharing and coverage restrictions that change the patients' marginal cost of use, or managed competition, which may turn insurers into prudent buyers of care.

Under managed competition, supply and demand determine the allocation of insurance contracts sold by competing insurers to individuals, subject to government regulation of the benefit package and premium setting (e.g. through compulsory community rating), an open enrolment requirement, and a system of risk equalization. ${ }^{1}$ Managed competition may enhance efficient health care provision by giving insurers financial incentives to act as prudent buyers of health services on behalf of their subscribers. The role of managed competition in health care and its proper scope have been a

\footnotetext{
'Institute of Health Policy and Management, Erasmus University, Rotterdam, The Netherlands

${ }^{2}$ Ben Gurion University of the Negev, Taub Center for Social Policy, Israel ${ }^{3}$ School of Management \& Governance, Murdoch University, Australia; School of Economics, University of Bologna, Italy

${ }^{4}$ Department of Economics, Katholieke Universiteit Leuven, Belgium ${ }^{5}$ Polynomics, Switzerland

${ }^{6}$ Institute for Health Services Management, University of Duisburg-Essen, Germany

${ }^{7}$ Institute of Health Policy and Management, Erasmus University Rotterdam, The Netherlands
}

Corresponding author:

Pieter Bakx, P.O. Box 1738, 3000 DR Rotterdam, The Netherlands. Email: bakx@bmg.eur.nl 
major topic in health economics. ${ }^{1-3}$ Whether managed competition may be an appropriate way to finance LTC depends, among other things, on whether insurers can be provided with appropriate instruments and incentives to act as prudent buyers of LTC and whether a sufficient proportion of consumers will (be able to) act as critical buyers of LTC benefits offered by insurers. ${ }^{2}$

In practice, several versions of demand-side strategies have been implemented in four European countries that finance LTC through public insurance as opposed to subsidizing LTC from general taxation - Belgium, Germany, the Netherlands and Switzerland.

We focus on two questions. Do the ways in which demand-side strategies are currently implemented in these countries provide incentives to curb the impact of moral hazard on allocative efficiency and expenditures? And do these strategies have adverse effects on universal access to basic LTC? The answers to these questions highlight the consequences of design choices regarding demand-side measures. These answers generate hypotheses about causal relationships between demand-side measures and outcomes and suggest how each of these countries - and other countries with similar policies - may change their policies. The variation in demand-side measures may have many reasons. It is unlikely, however, that this variation is due to differences in the technical feasibility of these measures because this is largely determined by the LTC financing system, which is quite similar in all four countries. Hence, their experience with the various measures may be transferable across these countries.

\section{Strategies to reduce moral hazard}

Policies targeting patients aim to limit their demand. One such policy is 'independent eligibility assessment'. In health care, eligibility is usually determined by providers. But to limit the influence of providers, in LTC this task is often entrusted to independent assessment agencies. Eligibility assessment aims to curb unnecessary LTC use by limiting the care that patients can receive. Assessment criteria help to ensure formal care is restricted to that which is needed. Criteria regarding the availability of informal care are used to prevent substitution of formal care for informal care.

Governments may also curb demand for LTC through cost sharing, providing benefits in-kind, reimbursement limits, coverage restrictions and means testing. Cost sharing reduces the gap between the total marginal costs and the marginal costs to the patients and thus limits moral hazard and its negative consequences. The impact of cost sharing on efficiency depends on how it is designed and how patients react to it. In the absence of transaction costs, the ideal cost sharing arrangement is tailored to the price sensitivity of each patient. So cost sharing that takes at least some of the differences in price sensitivity into account is therefore more efficient than having a single tariff for everyone. Moreover, cost sharing that accounts for differences in income and wealth guarantees financial access to LTC for poorer individuals.

Providing benefits in-kind rather than giving cash benefits may limit moral hazard by making claiming unnecessary benefits less attractive. However, the net impact of the restriction is unclear as it limits the ability of patients to coordinate formal and informal LTC and ensure efficient substitution, which might generate substantial gains if they are sufficiently informed. In-kind transfers are unlikely to have a direct impact on universal access to basic LTC.

Reimbursement limits and coverage restrictions prevent excessive use by limiting the amount and the types of benefits that patients with LTC may claim. Strict reimbursement limits and coverage restrictions may have an adverse impact on universal access to basic LTC: while more affluent patients are able to pay for the basic care that is not covered, poorer patients may not.

A means test limits some potential beneficiaries through eligibility criteria related to income or wealth. Therefore, it reduces LTC expenditures but does not affect the allocation in other ways; a means test does not prevent inefficient substitution and overuse by eligible individuals. The benefits need to be set at a low level to prevent strategic behaviour, such as through transfers within the family. ${ }^{4}$ When the benefits are set at a very low level, means testing may impede universal access to basic LTC.

Another demand-side strategy is managed competition, which aims to provide third party payers with incentives to act as prudent buyers of care on behalf of their patients. These incentives come from the need to compete for enrolees and from making insurers financially accountable for (part of) the difference between risk adjusted capitation payments they receive for their enrolees and the incurred expenses. ${ }^{1}$

\section{Current policies targeting the consumer}

This section discusses the demand-side measures targeting patients in each of the four countries. All four countries have a public insurance system for LTC and at least some mandatory public insurance coverage for home care and institutional care. But the financing and organization of LTCs differs in four aspects between these countries (Table 1): the overall share of gross domestic product (GDP) spent on LTC for the elderly; the LTC financing mix, including the importance of public spending on LTC; public insurance coverage for LTC; the design of the public LTC financing system. 


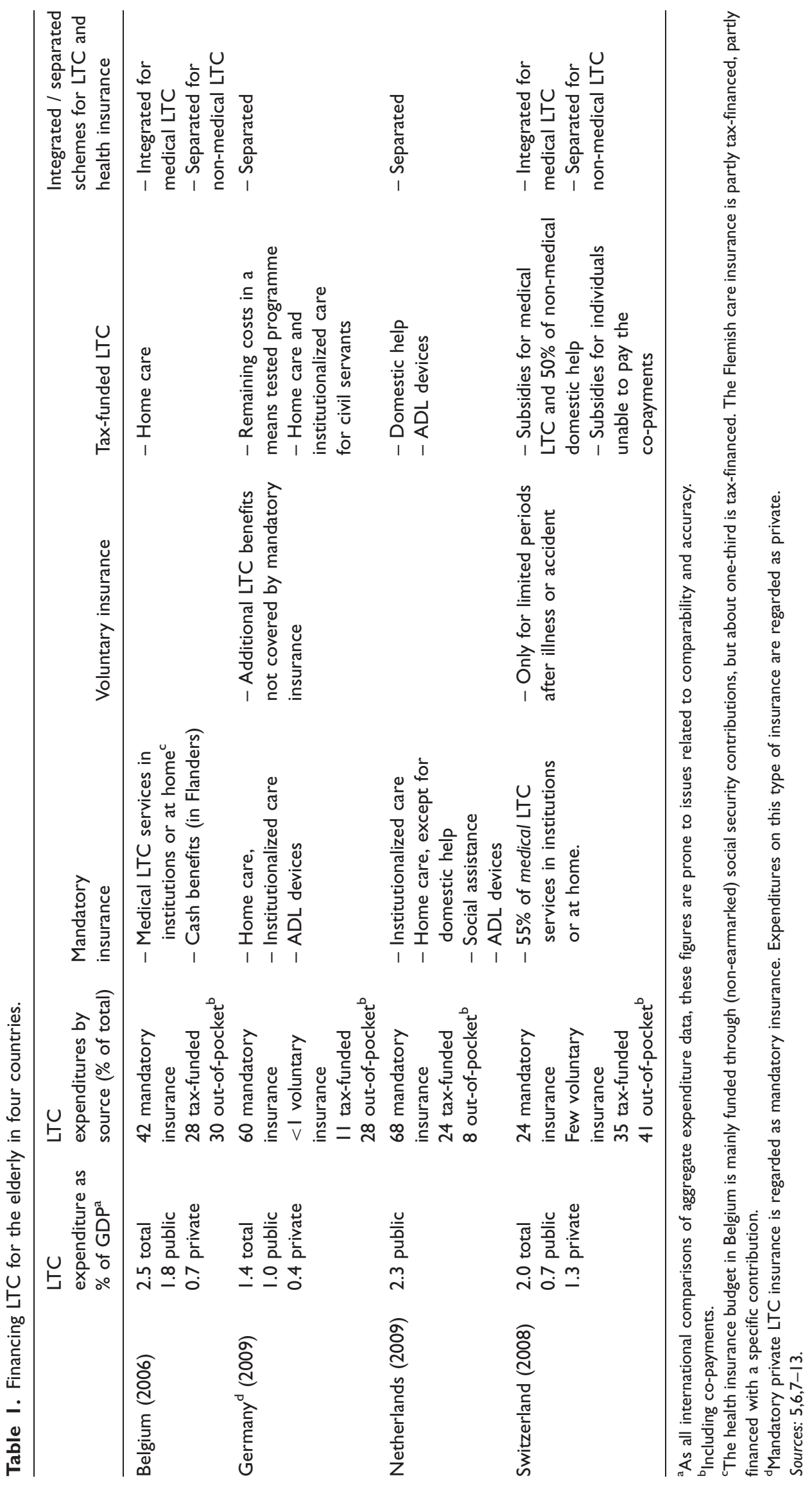


Table 2. Demand-side measures and the expected effects on efficiency and access.

\begin{tabular}{|c|c|c|}
\hline Policy measure & $\begin{array}{l}\text { Expected effect } \\
\text { on efficiency }\end{array}$ & $\begin{array}{l}\text { Expected effect on } \\
\text { access to LTC }\end{array}$ \\
\hline \multicolumn{3}{|l|}{ Belgium } \\
\hline Standardized, independent eligibility assessment & Positive & Undetermined \\
\hline Limited benefit package & Positive $^{\mathrm{a}}$ & Negative $^{\mathrm{b}}$ \\
\hline $\begin{array}{l}\text { Co-payments, related to income, assets, household composition } \\
\text { and type and duration of care }\end{array}$ & Positive $^{\mathrm{a}}$ & Limited \\
\hline $\begin{array}{l}\text { Managed competition: limited financial risk, extensive risk } \\
\text { adjustment }\end{array}$ & Limited & Limited \\
\hline \multicolumn{3}{|l|}{ Germany } \\
\hline $\begin{array}{l}\text { Standardized, independent eligibility assessment based on health } \\
\text { and disability }\end{array}$ & Positive & Undetermined \\
\hline Low, fixed-level benefits & Positive & Negative \\
\hline Limited benefit package & Positive $^{\mathrm{a}}$ & Negative $^{\mathrm{b}}$ \\
\hline Cash benefits & Undetermined $^{c}$ & Limited \\
\hline \multicolumn{3}{|l|}{ Netherlands ${ }^{d}$} \\
\hline $\begin{array}{l}\text { Standardized eligibility assessment based on health, disability and } \\
\text { informal care availability }\end{array}$ & Positive & Undetermined \\
\hline Co-payments: income-related and asset-related & Positive $^{\mathrm{a}}$ & Limited \\
\hline Cash benefits & Undetermined $^{c}$ & Limited \\
\hline \multicolumn{3}{|l|}{ Switzerland } \\
\hline Eligibility determined by providers, insurers may audit & Positive & Undetermined \\
\hline Limited benefit package for non-medical LTC & Positive & Negative ${ }^{b}$ \\
\hline Co-payments and deductibles for medical LTC & Positive $^{\mathrm{a}}$ & Negative \\
\hline $\begin{array}{l}\text { Managed competition: full financial risk for insurers, limited risk } \\
\text { adjustment }\end{array}$ & Undetermined $^{\mathrm{e}}$ & Negative \\
\hline
\end{tabular}

${ }^{a}$ Out-of-pocket payments reduce the gap between the total marginal cost and the marginal cost for the care recipient and thus improve the allocation by making the care recipient more cost conscious. But out-of-pocket payment may also cause to forego necessary care and may thus lead to higher demand for care in the long run. The impact of out-of-pocket payments on efficiency is positive if the former effect dominates the latter.

${ }^{\mathrm{b}}$ Assistance from the local and federal government may provide relief.

${ }^{c}$ Assuming that the choice between cash benefits and in-kind provision does not affect the health of the recipient, the impact on efficiency depends on whether the gain from efficient substitution between formal and informal care and the discount exceed the decrease in efficiency resulting from excessive claims to benefits.

${ }^{2} 2014$ situation.

${ }^{\mathrm{e}}$ The impact of full financial risk for insurers combined with limited risk adjustment on efficiency depends on the relative magnitude of i) the positive impact of financial risk on the effort that the insurer puts in acting as a prudent buyer of LTC and ii) the negative impact of the limited risk adjustment on the quantity and the quality of the care that the insurer contracts and on how it allocates this care.

We will first discuss policies in Belgium and Switzerland, which have integrated public insurance for health care and LTC. Next we discuss policies in Germany and the Netherlands, which in 2014 had separate public insurance schemes for LTC.

\section{Belgium and Switzerland}

Coverage for health care and for medical LTC is integrated in the public health insurance scheme (Table 1). Medical LTC is defined as the assessment of needs and provision of advice, medical care and support with Activities of Daily Living. ${ }^{9,10}$ Non-medical home care services, which are not covered through the integrated public insurance scheme, are financed by local and regional governments. Cantons in Switzerland, for example, provide subsidies for domestic care. Furthermore, they pay part of the LTC costs that are not paid by health insurers, whose contribution is fixed at roughly $55 \%$ of the costs of medical LTC. In Belgium, the organization and funding of non-medical home care is taken up by the regional governments and there are cash allowances to pay for assistance. A cash allowance is paid out to the disabled who are at least 65 years of age. The amount depends on the recipients' use of care and on their financial situation. In Flanders, a complementary cash allowance is a fixed amount for all disabled, regardless of their age, income or wealth. ${ }^{7}$ 
Belgium and Switzerland rely heavily on cost sharing as a strategy to counteract moral hazard (Table 1). In Switzerland, cost sharing consists of deductibles and co-payments. These co-payments are independent of income but poor individuals are eligible for subsidies. In Belgium, co-payments are income-related and capped while the additional cash benefits at the national level are means-tested.

The demand is further constrained by excluding some LTC services from the benefit package, such as accommodation costs. ${ }^{710}$ Furthermore, benefits are provided in kind. Yet, in Belgium additional cash benefits are available to compensate the elderly for the additional costs of living in poor health and domestic help is subsidized by government service vouchers. ${ }^{7}$ In Belgium, eligibility for medical LTC and the means-tested national cash allowances for assistance is assessed by a federal government service doctor according to national guidelines focusing on health and disability; eligibility assessment for cash benefits for non-medical LTC is done at the regional level. Home care providers are required to give priority to low-income patients (Wallonia) and patients without informal care (Flanders). ${ }^{10}$ In Switzerland, eligibility is assessed by providers and is based not only on criteria related to disability and health status but, for non-medical LTC only, also on criteria related to the availability of informal care. Both Swiss and Belgian insurers have a formal role in need assessment by conducting audits and thus they can indirectly influence the eligibility decisions.

\section{The Netherlands and Germany}

The Netherlands and Germany have separate public insurance schemes for LTC and either regional single payers (the Netherlands - until 2015) or sickness funds and private insurers (Germany) organize LTC and contract LTC providers. Eligibility is assessed according to national guidelines and entrusted to independent agencies in both countries, although in the Netherlands providers can in some cases perform reassessments. Consequently, providers and insurers can only indirectly, if at all, influence eligibility decisions. The eligibility criteria are related to disability and health status. In the Netherlands, eligibility for non-medical LTC also depended on the availability of informal care. ${ }^{11-13}$

The amount of LTC benefits in Germany depends on the level of disability - four benefit levels are distinguished - and on the patient's choice to live at home or move to a nursing home but does not depend on income or actual use. The benefits are usually not sufficient to cover the costs of LTC and patients pay the difference. These substantial out-of-pocket payments are believed to make patients cost-conscious. Therefore, moral hazard is currently not considered a major issue. ${ }^{14}$
Substantial cost sharing may endanger access to good quality LTC, particularly for poorer patients. The out-of-pocket payments may be too high for them and a separate means-tested programme covers part of the out-of-pocket payments for this group. In the Netherlands, co-payments are lower than in Germany and income-related. Furthermore, coverage is more restricted in Germany than in the Netherlands. For instance, the costs of accommodation in LTC institutions are covered by LTC insurance in the Netherlands but not in Germany. ${ }^{11,12}$ Indeed, poorer patients in Germany have less access to formal LTC than affluent individuals, while in the Netherlands LTC use is not associated with income. ${ }^{13}$

In both countries, patients can opt for cash benefits but it is lower than the monetary value of in-kind transfers. There is a discount of $25 \%$ in the Netherlands and of $50 \%$ in Germany. ${ }^{11,12}$

\section{Current policies targeting the insurer}

Managed competition among risk bearing insurers may encourage them to promote efficiency while guaranteeing access. The potential of managed competition depends on the ability to empower the competing insurers and to mitigate potential adverse effects of the financial incentives for efficiency. That is, being a prudent buyer of LTC and ensuring an appropriate allocation of LTC should positively affect an insurer's financial position. Three important determinants of the insurers' incentives are: whether the insurers bear any financial risk; if so, whether risk adjustment ensures that this financial risk provides appropriate incentives for efficiency; and whether health insurance and LTC insurance are integrated.

\section{Financial risk and risk adjustment}

Managed competition involving mandatory cross-subsidies between risk groups (e.g. through communityrated premiums), financial risk for insurers and competition among insurers may give these insurers strong financial incentives for selection. In public insurance schemes with managed competition, these incentives for risk selection are typically reduced by a system of risk equalization. ${ }^{1}$ Finding risk adjusters that reduce insurers' incentives for risk selection against patients needing LTC yet preserve the incentives for efficiency is a major challenge. ${ }^{1,2,15}$

So far, the experience with financial risk and risk equalization in LTC insurance is limited. In the Netherlands (until 2015) and Germany, insurers do not compete for patients and are retrospectively compensated from a central fund for providing LTC coverage and therefore are not at risk. ${ }^{11,12}$ 
Consequently, they play little role in promoting efficient use or provision of LTC. By contrast, in Belgium and Switzerland, LTC is partly covered through the health insurance scheme and insurers compete and bear financial risk. In these countries, insurers receive risk-adjusted subsidies for their enrolees. In Belgium, the financial risk for insurers is limited to $8 \%$ of losses incurred on medical expenses. In Switzerland, insurers bear the full financial risk.

Belgium is the only country with a risk equalization scheme that compensates health insurers for having enrolees using LTC. However, for two reasons it is unclear whether this compensation is adequate and thus counteracts risk selection. First, insurers bear only limited financial risk and competition among insurers is weak. ${ }^{16,17}$ It is therefore not clear whether the current risk adjusters would be sufficient to prevent risk selection if the degree of financial risk and competition are substantial. Second, the adequacy of the risk adjustment scheme may depend on the type of LTC services covered: medical LTC may be more predictable than non-medical LTC because the latter is partly contingent on the availability of social support.

The current Belgian risk-adjustment formula contains six variables that are clearly related to LTC use. Two variables, living alone and being a widow, widower or orphan, meet the criteria for good risk adjusters, ${ }^{1}$ but their validity is doubtful because it includes individuals of all ages. The other variables included in the risk adjustment formula are based on past or current entitlements, e.g. having a long term condition, which is determined using drug prescriptions. ${ }^{17}$ To date, there is no evidence that perverse incentives from risk adjustment based on past LTC use have affected insurers' behaviour.

In contrast to the extensive risk adjustment scheme in Belgium, the Swiss formula for risk-adjusted subsidies only includes age, sex and the previous year's inpatient stays, including to nursing homes, and hence picks up little variation in expected LTC expenditures. Therefore, incentives to select against patients needing LTC are strong. Furthermore, because inpatient stays increase next year's capitation payment but home care does not, insurers have incentives to institutionalize their enrolees, even more so if it may lower expenditures.

\section{Integration of health and LTC insurance}

Managed competition may be expanded to LTC by integration into public insurance or by introducing managed competition in a separate LTC insurance scheme.

Integration is necessary to avoid inefficient substitution of care, discontinuity of care and excessive hospitalization. But integration may only lead to efficient substitution of LTC and health care if insurers are at risk for both types of care and have appropriate incentives. If insurers are only at risk for health care expenditures, however, as is currently the case in Germany and the Netherlands, integration may result in inefficient substitution of LTC for medical care as long as insurers are not at risk for LTC expenses. Furthermore, integration may come at the cost of increased risk selection if risk adjustment for LTC is inadequate.

\section{Conclusion}

Comprehensive, affordable and universal public insurance for LTC ensures that everyone has financial access to care. Yet, unconstrained public LTC insurance is likely to suffer from moral hazard, which may result in inefficient allocation and excessive expenditures. These negative consequences may be limited through, among other things, demand-side strategies targeting the patient or the insurer.

In all four countries, the adverse impact of moral hazard on efficiency is controlled through demand-side measures, yet the importance of each and hence their net impact on efficiency and universal access vary. The effect that demand-side measures are expected to have on the efficiency of the system and the access to LTC could guide future research.

Managed competition has been pursued in Belgium and Switzerland and, since 2015, in the Netherlands as home care has been transferred from public LTC insurance into the health insurance scheme. A crucial precondition for the effectiveness of managed competition in LTC is to provide insurers with appropriate incentives. However, the prospects of fulfilling this precondition are unclear because little is known about the feasibility of adequate risk equalization for LTC and the specific actuarial features of LTC use may make developing adequate risk adjusters difficult. In addition, incentives for efficiency depend on whether health insurance and LTC insurance are integrated, necessary to avoid inefficient substitution of care, discontinuity of care and excessive hospitalization. But integration only has a positive impact if the insurers have the appropriate incentives.

Appropriate risk adjusters for LTC use are not only a necessary precondition for effective managed competition in public LTC insurance but may also be important for managed competition in health insurance. Even in a separate health insurance scheme, competing health insurers have an incentive to select against patients needing LTC if, after risk equalization, they have higher expected health care expenditures than others. This situation seems to be relevant for all countries with such a scheme because even in the case of the 
sophisticated Dutch risk equalization scheme, health insurers currently incur substantial losses on the medical cost of LTC patients. ${ }^{18}$

In addition to the preconditions ensuring appropriate incentives for insurers, there are others necessary for successful managed competition. For example, insurers need to be able to prevent providers giving excessive (or excessively expensive) services because people are covered by public LTC insurance. ${ }^{3}$ Hence, insurers need to be able to negotiate prices, volume and quality with providers. Currently, in none of the four countries did insurers negotiate contracts with LTC providers; volume and prices are largely or fully determined by the government. ${ }^{7,10,12,19}$ Only in Germany, insurers collectively negotiate prices with each provider and have somewhat more room for negotiations than in other countries as there are no supply constraints. ${ }^{16}$ So at best, insurers in the four countries can negotiate quality and steer patients towards well-performing providers.

In addition to these concerns, there are institutional and cultural preconditions for managed competition, such as the presence of a sufficient number of wellinformed patients who can discipline insurers to contract efficient and good quality LTC. ${ }^{20}$ Even when managed competition is technically, institutionally and culturally feasible, the broader question is which model is the most appropriate for financing and organizing the provision of LTC services. To answer this question, a full comparison of alternative options for publicly funding and purchasing LTC is required.

\section{Acknowledgement}

We thank Shuli Brammli-Greenberg and Wynand van de Ven for comments. This study is part of the Netspar theme Health and Income, Work and Care across the LifeCycle II.

\section{Funding}

This research received no specific grant from any funding agency in the public, commercial, or not-for-profit sectors.

\section{References}

1. Van de Ven WPMM and Ellis RP. Risk adjustment in competitive health plan markets. In: Cuyler AJ and Newhouse JP (eds) Handbook of health economics. Vol. 1, Amsterdam: Elsevier Science, 2000.

2. Van de Ven WPMM and Schut FT. Should catastrophic risks be included in a regulated competitive health insurance market? Soc Sci Med 1994; 39: 1459-1472.

3. Van de Ven WPMM, Beck K, Van de Voorde C, et al. Risk adjustment and risk selection in Europe: 6 years later. Health Policy 2007; 83: 162-179.
4. Cremer H and Pestieau P. Means-tested long-term care and family transfers. Working Paper 492. Toulouse School of Economics, 2014.

5. OECD. Help wanted? Providing and paying for long-term care. Paris: OECD, 2011.

6. CVZ. Baten AWBZ, 2007-2011. http://www.cvz.nl/zorg cijfers/awbz-baten/awbz-baten.html (2011, accessed 30 September 2011).

7. Willemé P. The Belgian system of long-term care. Federal Planning Bureau Working Paper, no. 7-10, 2010.

8. OECD. Health expenditure and financing. http://stats. oecd.org/Index.aspx (2011, accessed 30 September 2011).

9. Weaver F. Long-term care financing in Switzerland. In: Costa-Font $\mathrm{J}$ and Courbage $\mathrm{C}$ (eds) Financing longterm care in Europe. Institutions, markets and models. Basingstoke: Palgrave Macmillan, 2012.

10. Willemé P, Geerts J, Cantillon B, et al. Long-term care financing in Belgium. In: Costa-Font $\mathrm{J}$ and Courbage $\mathrm{C}$ (eds) Financing long-term care in Europe. Institutions, markets and models. Basingstoke: Palgrave Macmillan, 2012.

11. Rothgang H. Social insurance for long-term care: An evaluation of the German model. Soc Policy Admin 2010; 44: 436-460.

12. Schut FT and Van Den Berg B. Sustainability of comprehensive universal long-term care insurance in the Netherlands. Soc Policy Admin 2010; 44: 411-435.

13. Bakx P, de Meijer C, Schut FT, et al. Going formal or informal, who cares? The influence of public long-term care insurance. Health Econ. Epub ahead of print 2014. DOI: $10.1002 /$ hec. 3050

14. Rothgang $\mathrm{H}$ and Igl G. Long-term care in Germany. Jpn J Soc Secur Policy 2007; 6: 55-84.

15. Bakx P, Schut FT and Van Doorslaer E. Can risk adjustment prevent risk selection in a competitive long-term care insurance market? Int $J$ Health Econ Manage. Epub ahead of print 2015. DOI: 10.1007/s10754-0159163-3.

16. Paolucci F, Schut FT, Beck K, et al. Supplementary health insurance as a tool for risk selection in mandatory basic health insurance markets. Health Econ Policy Law 2007; 2: 173-192.

17. Schokkaert E and Van de Voorde C. Belgium's health care system: should the communities/regions take it over? Or the sickness funds? Re-Bel e-book 10. http:// www.rethinkingbelgium.eu/ (2011, accessed 20 October 2011).

18. Stam P and Van de Ven WPMM. De harde kern van de risicoverevening. Economisch Statistische Berichten 2008; 93: 104-107.

19. GD. Die neue Pflegefinanzierung. www.gd.zh.ch (2011, accessed 11 February 2011).

20. Van de Ven WPMM, Beck K, Buchner F, et al. Preconditions for efficiency and affordability in competitive healthcare markets: are they fulfilled in Belgium, Germany, Israel, the Netherlands and Switzerland? Health Policy 2013; 109: 226-245. 